\title{
MODELO FORDISTA: TRAÇOS DO PROCESSO DECISÓRIO NA ADMINISTRAÇÃO FORD
}

\author{
Frederico Bartels ${ }^{12}$ \\ "Can you imagine Jerry Ford sitting in this chair?" - Richard Nixon ${ }^{3}$
}

\begin{abstract}
Resumo
0 artigo faz uso do modelo de Mitchell sobre sistema de aconselhamento presidencial para estudar e analisar as atividades do Conselho de Segurança Nacional do presidente Gerald R. Ford durante a crise do Mayaguez. 0 modelo de Mitchell é baseado em duas variáveis: centralização e formalização. A centralização é medida em alta e baixa: Na alta centralização o foco é no presidente; na baixa centralização, o presidente tende a não estar presente. A formalização lida com como os assessores têm acesso ao sistema de tomada de decisão: Se o sistema tem regras de procedimento fortes ele é formal; se as regras de procedimento são menos rígidas, tem-se um sistema informal. De forma extremamente resumida, este é o modelo.
\end{abstract}

A crise do Mayaguez se deu no início da administração Ford, em meados de maio de 1975. Dada a recente evacuação das tropas americanas do Vietnã, pode-se afirmar que havia uma necessidade, por parte do governo americano, de demonstração de força. As minutas das reuniões do Conselho de Segurança Nacional que ocorreram entre 12 de maio e 15 de maio de 1975 foram utilizadas como subsídio para a pesquisa e como fonte de informações, com o objetivo de determinar o tipo de processo decisório ocorrido, de acordo com o modelo de Mitchell. 0 artigo conclui que existem traços de ambos os sistemas formal altamente centralizado e o de baixa centralização - neste caso específico.

\section{Palavras Chave}

Política Externa Americana, Conselho de Segurança Nacional, Presidência de Gerald Ford, Mayaguez

\footnotetext{
1 Frederico Bartels é graduando em Relações Internacionais da Pontifícia Universidade Católica de Minas Gerais. Seu e-mail de contato: frederico.bartels@gmail.com
}

${ }^{2} \mathrm{O}$ autor gostaria de agradecer o Instituto de Relações Internacionais da PUC Rio pela oportunidade e pela prontidão da equipe de Cadernos de Relações Internacionais. Gostaria de agradecer nominalmente a Amanda Caldeira e Cíntia Ribeiro por preciosas correções e sugestões que auxiliaram na clareza deste texto. Imprecisões e omissões são de total responsabilidade do autor.

3 apud Gould, 2003. 


\begin{abstract}
The article makes use of the Mitchell model on Presidential advisory systems to study and analyze the activities of the National Security Council under President Gerald R. Ford during the Mayaguez crisis. Mitchell's model is based on two variables: centralization and formalization. Centralization is measured in high or low, whereas the high centralization is a focus on the President and in the low, the President tends to be absent. Formalization concerns how the advisor has access to the decision-making system: if the system has strong rules of procedure, it is formal; if the rules are more relaxed, an informal one. In a very short form, this is the model.

The Mayaguez crisis took place in the beginning of the Ford Administration, in mid-May 1975. The crisis also had on its component the recent evacuation of American troops from Vietnam, therefore there was a sense of necessity for a show of strength. The minutes of the National Security Council meeting that took place from May 12 to May 15, 1975, were used to subside the research and to provide information to access the type of decision-making according to Mitchell's model. The article concludes that there are traces of both - formal high centralized and low centralized system.
\end{abstract}

\title{
Keywords
}

American Foreign Policy, National Security Council, Gerald Ford administration, Mayaguez.

\section{Introdução}

0 presente artigo tem como objetivo explorar o processo decisório que levou à ação na situação que envolveu o navio Mayaguez dentro do escopo do Conselho de Segurança Nacional dos Estados Unidos da América (NSC). 0 trabalho tem como preocupação central questões de Análise de Política Externa representadas por Hudson $(2005,2007)$ e Hill (2003). Nesta linha, os constrangimentos institucionais, assim como a formação de elementos importantes do governo, são explanadas para garantir uma visão mais completa do problema.

\section{O Conselho que Assegura a Nação}

O Conselho de Segurança Nacional foi criado em 1947 com o intuito de centralizar o processo decisório em segurança nacional, como forma de melhor servir à presidência na tomada de decisão (Rothkopf, 2005, Inderfurth; Johnson, 2004; Prados, 1991). Seu objetivo seria “(...) 
aconselhar o presidente no que diz respeito à integração das políticas doméstica, externa e militar relacionadas à segurança nacional (...)" (U.S. Congress, 1947, p.24) 12 , fazendo com que a instituição presidencial seja o centro das preocupações do NSC. Nesse sentido, o NSC é um sistema de aconselhamento que auxilia o presidente na tomada de decisão (Mitchell, 2005). Adicionalmente, é um sistema extremamente moldável, pensado para adaptar-se às necessidades do ocupante da Casa Branca ${ }^{3}$. Rothkopf (2005) e Prados (1991) trabalham com diferenciações importantes que cada presidente confere ao Conselho, mostrando que o Ato de Segurança Nacional de 1947 criou realmente uma instituição subordinada à presidência4. Nesse sentido, "[c]ada presidente irá desenvolver mecanismos que lhe cabem melhor. Entre outros elementos, o sistema político estabelecido irá refletir as idiossincrasias da química interpessoal" (Rockman, 1981, p.304), evidenciando o caráter personalista que cada presidente confere à instituição.

Apesar de concentrar a cúpula decisória de cada administração, o NSC, como uma instituição, não tem nenhum poder de facto: este emana da qualidade e influência das discussões e das ações individuais de seus membros como chefes de burocracias. 0 papel primário do Conselho é auxiliar o presidente a tomar melhores decisões, e não tomar as decisões por ele. Não obstante, a influência do NSC no processo decisório é sempre considerável ${ }^{5}$. É interessante notar que o cargo que é criado para dirigir o Conselho ficou sendo conhecido como assistente presidencial para Assuntos de Segurança Nacional, mostrando mais uma vez a proeminência do chefe do Executivo sobre o Conselho. Apesar desta proeminência, deve-se ressaltar o ponto elaborado por Neustadt (1990) e Sorensen (2005) de que o presidente não é capaz de simplesmente expressar ordens e esperar que elas sejam cumpridas, uma vez que o grande poder presidencial seria o de convencimento. Esta complicação fica evidente quando se considera a divisão de Hilsman (1987) entre burocratas de carreira e membros ligados à administração temporária, uma vez que os segundos devem representar sua burocracia em face ao presidente e devem representálo face à burocracia permanente ${ }^{6}$.

A burocracia permanente é uma força que é levada em consideração pelos estudos de Análise de Política Externa, uma vez que esta é capaz de afetar o processo decisório e o de implementação de políticas 
públicas (Hudson, 2007; Hill, 2003). A cisão entre a burocracia permanente e os membros indicados pelo presidente é inerente ao sistema americano e garante a continuidade de certas políticas, apesar das diferenças partidárias. No limite, os dois grupos têm de lidar uns com os outros, resolvendo seus conflitos dentro da prática política regular.

A necessidade institucional de criação do Conselho de Segurança Nacional deu-se devido à insatisfação americana com o desempenho de suas instituições, uma vez que os governantes sentiram que faltava uma maior unificação no comando da Segunda Guerra Mundial7 ${ }^{7}$. A tradição governamental americana, que é muito bem ilustrada pelos escritos de Hamilton, Madison e Jay (1788/1982), coloca que os poderes devem ser divididos para que não possam ser usurpados por somente um indivíduo ${ }^{8}$. Assim, na organização do Poder Executivo há uma divisão de tarefas relacionadas às relações internacionais, que são identificadas por Tocqueville (1835/2004) como sendo uma tarefa do presidente e do Senado, em, pelo menos, três departamentos ${ }^{9}$.

O NSC, de maneira alguma, vai contra esta tradição da divisão de poderes entre diferentes instituições, uma vez que o grande interesse do Conselho é que as diferentes partes do aparato americano voltado para as relações internacionais se comuniquem melhor. A divisão de tarefas permanece, mas o presidente ganha em capacidade de fazer com que a sua opinião seja a prevalecente com menor esforço, como coloca Neustadt (1990). Kissinger (2001, p.173-4) afirma que “(...) este foro [NSC] é assessor; o presidente não é obrigado a seguir suas recomendações. Durante meu tempo de serviço, nem Nixon nem Ford solicitaram qualquer votação". Assim, a necessidade institucional do NSC é colocar os diferentes departamentos em contato para que estes possam construir políticas de segurança nacional de forma mais coerente.

O Conselho de Segurança Nacional passou por diversas transformações ao longo dos anos, como indica Rothkopf (2005), sendo uma delas de extrema importância para o estudo do processo de tomada de decisão em política externa americana: a capacidade de agência de seus membros não-estatutários. O NSC, a partir do governo Eisenhower, começou a contar com uma equipe própria para processamento de dados, com a composição de informações para o presidente e com a análise própria10. Assim, “[o] que emerge desta história é uma equipe 
do NSC usada por cada presidente de uma maneira que reflita suas preferências individuais e seu estilo de trabalho" (Tower; Muskie; Scowcroft, 1987, p.13). Portanto, o Conselho é um dos órgãos do Executivo que sofre grandes alterações, não só na composição da equipe, mas também nas funções e no funcionamento colocados pelo líder do Executivo ${ }^{11}$. Muitos presidentes chegam a abordar, em suas campanhas presidenciais, a forma como pretendem lidar com o Conselho caso sejam eleitos, como demonstra Kolodziej (1969).

\title{
Heranças e Mudanças
}

Gerald Ford assume a Casa Branca em um momento turbulento da história americana, herdando em agosto de 1974 um NSC sob a gestão de Henry Kissinger. 0 sistema montado por Nixon almejava concentrar o processo decisório em suas mãos e deixar o seu assessor geri-lo, como indica Bundy (1988). O desenho do sistema na administração tinha como objetivo principal alienar o Departamento de Estado do processo de tomada de decisão, devido a uma profunda desconfiança do presidente em relação à burocracia permanente que geria o departamento (Kimball, 1998, Bundy, 1998). Assim, temos que:

\begin{abstract}
Nixon tinha uma capacidade tremenda, experiência e desejo de comandar a política externa. Então você tinha um presidente que desejava controlá-la, que não confiava na burocracia, especialmente no Departamento de Estado, apontando que eles eram um apanhado ou de burocratas incapazes de pensar ou de democratas de esquerda, ou de ambos (Lord apud Rothkopf, 2005, p.127).
\end{abstract}

Esta desconfiança fez com que Nixon desejasse ainda mais concentrar a execução de política externa, pelo menos em áreas prioritárias, na Casa Branca $^{12}$. Bundy (1998) aponta que esta priorização do aparato próprio do Executivo para condução de política externa inicia-se ainda antes do começo da administração, representada pela participação de Kissinger na escolha de Rogers para o Departamento de Estado. 0 objetivo final era que "Nixon gostaria de fazer uso de profissionais novos de política externa, recrutados de fora do governo, portanto livrando-os da marca de estarem dentro da burocracia que Nixon desprezava tanto" (Mitchell, 2005, p.47). 
A formalização dos trabalhos do NSC na era Nixon dava-se a partir de dois tipos de documentos, ou duas séries: i) os Memorandos de Decisões de Segurança Nacional (NSDM - National Security Decision Memoranda); e ii) os Memorandos de Estudos de Segurança Nacional (NSSM - National Security Study Memoranda). Neste sentido, "[e]xistia os documentos de revisão ou documentos de estudos [NSSM] e existia também o documento decisório [NSDM]. E Henry [Kissinger] matinha uma grande disciplina sobre isto (...)" (Clarke apud Rothkopf, 2005, p.119). Este ponto da disciplina quanto ao formato dos documentos é um dos elementos apoiadores da tipologia de Johnson (1974), que coloca o sistema de Nixon como sendo formal ${ }^{13}$. Adicionalmente,

\begin{abstract}
Comitês entre agências produziam Memorandos de Estudos de Segurança Nacional (NSSMs) que ofereceriam as visões das agências nos assuntos mais importantes em pauta e forçavam as agências a pensar no futuro e a antecipar os desafios que elas iriam enfrentar. Documentos que tracejavam decisões políticas eram chamados, de maneira bem simples, Memorandos de Decisões de Segurança Nacional (NSDMs). Adicionalmente, o NSC produziria uma variedade de outros memorandos e revisões de políticas. (Rothkopf, 2005, p.117).
\end{abstract}

Portanto, o NSC de Nixon tem dois documentos guiadores dos trabalhos que são observados com algum rigor pelos participantes, mostrando traços de formalidade nos comportamentos de Nixon e Kissinger diante do sistema.

A partir destas informações, podemos reforçar o diagnóstico de Mitchell (2005) sobre a administração Nixon como sendo altamente centralizada e formal ${ }^{14}$. A alta centralização do sistema de aconselhamento é dada pela forte concentração do processo decisório na figura presidencial ${ }^{15}$. Já a formalidade do sistema dá-se pela forma com que este é organizado e com que as informações chegam ao presidente, ou ao tomador de decisão. Esta formalidade é composta de três características principais: i) hierarquia; ii) especialização de informações e conselhos; e iii) o fato de que o presidente, normalmente, não busca informações em meio aos seus conselheiros (ibid, p.24). Assim, temos que o sistema identificado para a administração Nixon seria caracterizado da seguinte maneira:

Líder avalia as opções apresentadas 
Líder expressa preferências gerais moldando opções de consideração

Guardião (Gatekeeper) age como um advogado e seleciona informações e acesso ao líder

Barganha e conflito são desencorajados no grupo; vozes dissidentes são excluídas.

Processo de tomada de decisão ordeiro e com procedimentos bem definidos

Solução dominante (ibid, p.48)

Desta forma, o sistema responderia aos anseios do presidente Nixon ao excluir parte do aparato regular de política externa americana do núcleo do processo decisório. Mitchell (2005) chega ao ponto em que todas as características acima descritas são partes recorrentes do processo decisório durante a administração Nixon, ficando somente a questão do processo de tomada de decisão ordeiro relegada ao segundo plano, por estar presente em somente $37 \%$ dos casos estudados ${ }^{16}$. Mitchell (2005, p.79) conclui que "[o] sistema de aconselhamento formalmente estruturado e altamente controlado de Nixon demonstra características consistentes com aquelas achadas na tipologia".

Não obstante, existem pontos do processo de tomada de decisão na administração Nixon que não são consideradas pela tipologia, uma vez que são julgadas por Mitchell (2005) como sendo a exceção à regra do sistema. Bartels e Ribeiro (2007) mostram situações de tomada de decisão nas quais há uma preocupação por parte de Kissinger e Nixon de incluir elementos que são excluídos em outros momentos, como os Secretários Rogers e Laird ${ }^{17}$, para que a mensagem da administração seja unificada. Apesar de existir momentos nos quais a tipologia estabelecida não é suficiente para explicar o processo decisório, esta é extremamente rica. Alterações pontuais em momentos específicos não invalidam a tipologia.

Esta é a herança do sistema NSC que Nixon deixa para Ford. Entretanto, no momento em que Ford assume, Kissinger ocupava a chefia do departamento de Estado, além do cargo de Assessor para Segurança Nacional. Portanto, houve uma unificação em somente um indivíduo de cargos com funções que se sobrepõem em alguns momentos. Scowcroft (2001, p.113) trabalhou sob ambos os presidentes e aponta, "[e]le [Nixon] levava os papéis para estudar, voltava com eles marcados e tomava suas decisões principalmente desta maneira. Ford era justamente o oposto. Ele gostava de se decidir enquanto escutava um debate sobre os assuntos envolvidos". Quando se considera o passado 
de ambos os presidentes, vemos ainda outra fonte de grande divergência entre ambos: enquanto Nixon estava majoritariamente envolvido com o Poder Executivo desde o governo Eisenhower, Ford tem um passado fortemente assentado no Poder Legislativo, tendo sido líder do Partido Republicano na Casa dos Representantes (House of Representatives) por cerca de oito anos (Nixon, 1978).

A experiência no Executivo faz com que o indivíduo tenha uma tendência a preocupar-se menos com o consenso e com o convencimento de outros, enquanto o passado envolvido no Legislativo tende a fazer com que a preocupação com angariar apoio para sua posição seja maior (Neustadt, 1990). Não obstante, estes termos não são categóricos, uma vez que o próprio Nixon demonstra uma preocupação com a concisão de sua administração em vários momentos (Bartels; Ribeiro, 2007; Kimball, 1998; Bundy, 1998; Kissinger, 2003).

0 ponto de transição foi a forma como o novo presidente lidou com o sistema já estabelecido, considerando-se que o NSC é moldado pelo presidente para atender às suas necessidades governamentais. Para isto, trabalhar com a tipologia de Mitchell (2005) e com estudos de caso é o caminho mais apropriado para determinar como o sistema funcionava. Assim, temos que um ponto de partida na declaração do presidente sobre o NSC, em geral:

\begin{abstract}
Logo após a guerra, por lei (sic), o Congresso aprovou uma lei colocando a criação do NSC. E o propósito do NSC era bem sólido. Um presidente iria ter diversas recomendações individuais do Departamento de Estado, Departamento de Defesa e do Departamento do Tesouro, todos pedindo pela aprovação presidencial. Até a criação do NSC, o presidente não tinha nenhum grupo profissional na Casa Branca que poderia avaliar essas recomendações de programa. Então o NSC foi estabelecido como um think tank para o benefício do presidente (Ford, 2001, p.79).
\end{abstract}

Este pensamento inicial contém traços de um sistema colegiado, em que o presidente teria uma grande preocupação em escutar a opinião de grande parte de seus assessores e, de certa forma, participar ativamente do processo decisório (Mitchell, 2005). Não obstante, não há nenhum indício do nível de centralização que o sistema passa a ter sob a administração Ford. É interessante notar que existe a possibilidade de mudança do sistema durante uma mesma administração e, portanto, uma grande probabilidade de mudança do 
sistema nesta transição. O próprio Mitchell (2005) já aponta estas ocorrências.

\section{Mitchell por Mitchell}

A tipologia desenvolvida por Mitchell (2005) leva em consideração duas variáveis que formam quatro possíveis tipos de organização do sistema de aconselhamento de um presidente. Assim, a partir da centralidade e da formalidade do sistema, definem-se os seguintes tipos de organização: i) formal com alta centralização; ii) formal com baixa centralização; iii) colegiado com alta centralização; e iv) colegiado com baixa centralização (Mitchell, 2005, p.25). 0 trabalho de Mitchell (2005) parte do ponto iniciado por Johnson (1974) e George (1980), para avançar em uma tipologia que possa englobar aspectos que são considerados importantes não só pelo próprio autor, mas pela literatura moderna da área. Neste sentido,

A grande tendência atravessando a literatura sobre a presidência é a importância da centralização dentro do sistema de aconselhamento, significando a extensão na qual o presidente impõe e centraliza o controle sob o fluxo de informações e a interação entre seus conselheiros (Mitchell, 2005, p.23, ênfase nossa).

A adição da centralização às considerações de Johnson (1974) e George (1980) permite que haja uma nova perspectiva e uma série diferente de impactos da tipologia na análise. Temos que "[o] argumento aqui apresentado sustenta que a centralização encontrada nestas diferentes literaturas cobre a falha da tipologia Johnson/George para refletir tipos de sistemas de administração previamente discutidos" (Mitchell, 2005, p.23).

Adicionalmente, é importante ressaltar que há uma grande diferença entre a tipologia construída por Johnson (1974) e George (1980) e a utilizada por Mitchell (2005) para traçar considerações sobre a formalidade, uma vez que "[a]s diferenças entre os modelos formais, colegiado e competitivo implicitamente contêm variações de centralização (...)” (ibid, p.23). Mitchell (2005) ainda coloca que o modelo competitivo seria somente uma variação do modelo colegiado, o que geraria redundâncias na formulação da tipologia. Eliminando esta redundância, Mitchell (2005) limita a questão da formalidade à 
possibilidade de organização formal, que seria “(...) composta de comitês especializados que são geridos por normas rígidas com decisões tomadas no topo pelo presidente" (ibid, p.10), e a organização colegiada na qual "(...) decisões são tomadas em uma atmosfera informal, onde há certo espírito de time" (ibid, p.10). Portanto, a primeira variável da formação da tipologia - a formalidade do sistema desdobra-se em formal e colegiado. Faz-se mister considerar que Mitchell (2005) coloca que a formalidade é presente em todos os sistemas de aconselhamento, em maior ou menor grau.

A segunda variável considerada na tipologia de Mitchell (2005) é a centralização do sistema na figura presidencial, sendo esta a capacidade presidencial de impor e centralizar o controle sob o fluxo de informação e interação entre os assessores (ibid,p.23). A variação na qual a centralização é trabalhada é entre um sistema com alta centralização e um sistema com baixa centralização. Assim, tem-se que a “[c]entralização é tratada como variando entre alta e baixa em relação aos sistemas formais e colegiado, portanto gerando quatro diferentes tipos de sistemas de aconselhamento" (ibid, p.24). A consideração das duas variáveis é que permite que a tipologia seja criada e que características que as definem sejam especificadas. Assim, tem-se, organizadamente, a tipologia de Mitchell (2005):

\begin{tabular}{|c|c|c|}
\hline & Formal & Colegiado \\
\hline 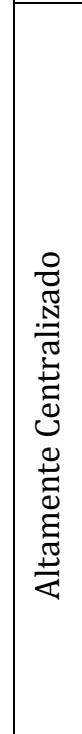 & $\begin{array}{l}\text { Líder avalia opções } \\
\text { apresentadas } \\
\text { Líder expressa } \\
\text { preferência geral } \\
\text { moldando as opções } \\
\text { consideradas } \\
\text { Guardião age como } \\
\text { advogado que } \\
\text { seleciona informações } \\
\text { e acesso ao presidente } \\
\text { Barganha e conflito no } \\
\text { grupo são } \\
\text { desencorajados, vozes } \\
\text { dissidentes são } \\
\text { excluídas. } \\
\text { O processo é ordeiro } \\
\text { com procedimentos } \\
\text { bem definidos }\end{array}$ & $\begin{array}{l}\text { Líder é membro } \\
\text { ativo do grupo, } \\
\text { guiando e } \\
\text { moldando as } \\
\text { deliberações } \\
\text { Líder faz com que o } \\
\text { grupo analise } \\
\text { diferentes opções } \\
\text { Ênfase na } \\
\text { construção de } \\
\text { consenso entre } \\
\text { assessores centrais } \\
\text { Responsabilidade } \\
\text { compartilhada } \\
\text { pelas decisões } \\
\text { Reuniões regulares } \\
\text { e freqüentes com } \\
\text { assessores centrais }\end{array}$ \\
\hline
\end{tabular}




\begin{tabular}{|c|c|c|}
\hline 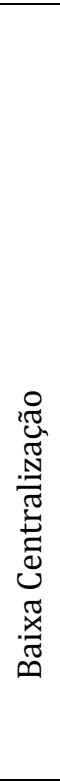 & $\begin{array}{l}\text { Líder escolhe entre as } \\
\text { opções apresentadas } \\
\text { Assessores competem } \\
\text { para ter suas } \\
\text { preferências } \\
\text { apresentadas ao líder } \\
\text { Guardião age como } \\
\text { intermediário neutro e } \\
\text { apresenta opções } \\
\text { Procedimentos podem } \\
\text { ser circulares } \\
\text { Barganha e conflito } \\
\text { dão-se no nível abaixo } \\
\text { do presidente }\end{array}$ & $\begin{array}{l}\text { Disposição para } \\
\text { delegar autoridade } \\
\text { para outros que } \\
\text { tenham } \\
\text { conhecimento } \\
\text { específico } \\
\text { Assessores são } \\
\text { instrumentais para } \\
\text { guiar a política } \\
\text { Menos ênfase na } \\
\text { construção de } \\
\text { consenso entre } \\
\text { assessores } \\
\text { Conflito e barganha } \\
\text { entre assessores } \\
\text { Não há um modo } \\
\text { regular de } \\
\text { interação com os } \\
\text { assessores }\end{array}$ \\
\hline
\end{tabular}

Quadro 1: Tipologias de Mitchell. Adaptado de Mitchell, 2005, p.25.

Estes são os parâmetros que este trabalho adotará para explicar o processo de formulação de política externa dentro do NSC do presidente Ford. As grandes incógnitas a serem trabalhadas são como um sistema que foi construído para alienar um cargo específico - o de secretário de Estado - irá funcionar quando o gestor primeiro do sistema passa a ocupar este cargo; e como o novo presidente modifica o sistema montado por um presidente anterior. Esta segunda questão fazse ainda mais pertinente quando se leva em consideração que o presidente Ford não teve o tempo de que os presidentes dispõem, normalmente, entre a eleição e a posse para organizar seu aparato de política externa. Além deste ponto, enquanto Nixon tinha um passado fortemente ligado ao Poder Executivo, Ford era um homem que tem sua experiência política centrada no Legislativo.

\section{Arrumando a Casa}

Ford torna-se o trigésimo oitavo presidente dos Estados Unidos no dia 9 de agosto de 1974. Neste mesmo dia, o presidente lança a NSDM 265 e, no dia 10, organiza uma reunião do NSC para traçar suas novas diretrizes (United States of America, 2001). Diz este memorando:

As provisões do NSDM 1 e NSDM 2, datados de 20 de janeiro, 1969, conforme emendadas e estendidas por Memorandos de Decisões de Segurança Nacional 
subseqüentes, que definem a organização e os procedimentos do Sistema do Conselho de Segurança Nacional, são reafirmadas e mantêm-se em efeito.

O Sistema do Conselho de Segurança Nacional deve me assistir no desempenho de minhas responsabilidades para assuntos de segurança nacional e o Conselho de Segurança Nacional deve continuar a ser o principal fórum para consideração de assuntos políticos que requerem a determinação presidencial. A operação do Sistema do Conselho de Segurança Nacional irá continuar sob a direção do Assistente do Presidente (Assuntos de Segurança Nacional). Comunicações para mim relacionadas a assuntos de segurança nacional devem ser transmitidas pelo Assistente do Presidente (Assuntos de Segurança Nacional).

Henry A. Kissinger é, por meio deste, designado como Assessor do Presidente (Assuntos de Segurança Nacional) (United States of America, 1974a).

Kissinger (2001) afirma que o início da administração Ford foi marcada por uma certa continuidade inicial do gabinete de Nixon, para mostrar que as instituições continuavam fortes e atuantes, garantindo uma sensação de segurança maior para o povo americano. Esta continuidade foi, porém, extremamente curta. Temos que:

A troca de Nixon por Ford foi particularmente complexa 0 primeiro presidente não-eleito, Ford não colheu os benefícios de uma campanha presidencial ao lado do antecessor, para poder, pelo menos, amealhar a aura refratada da vitória partidária. E também recebeu um governo desmoralizado por cerca de dois anos de pancadarias e catástrofes que envolveram a crise de Watergate. Como todos os vicepresidentes que ascendem à presidência, faltava-lhe tanto a constância de assessores políticos como a máquina político-partidária que impulsiona um Presidente eleito para o cargo (Kissinger, 2001, p.175).

Portanto, é um momento de turbulência com apoio reduzido, sendo necessário que houvesse uma re-conexão e um restabelecimento da confiança do presidente com seu povo. Não obstante, há uma mudança gradual do gabinete de Ford. Assim, "[a]o cabo de dezoito meses, todos os membros do gabinete, exceto dois (Bill Simon no Tesouro e eu 
[Kissinger] como secretário de Estado) foram trocados, assim como o diretor da CIA" (Kissinger, 2001, p.175). Mas é somente através da análise do desenrolar dos eventos de política externa que se pode ter uma imagem mais nítida de como se dava o processo decisório na administração Ford.

\section{Milhas náuticas, Containeres e Comunistas - Maio de 1975}

Um dos eventos mais memoráveis da administração Ford, em questões de segurança nacional, é o incidente com o navio Mayaguez, um navio cargueiro que foi apreendido pelos comunistas cambojanos, sob a liderança de Pol Pot ${ }^{18}$. Os mortos deste regime chegam à cifra de 1,2 milhões de mortos, o equivalente a um quinto da população entre abril de 1975, quando o Khmer Vermelho toma o poder, até o início de 1977. Grande parte destas mortes tem como causa o êxodo urbano forçado promovido pelo regime, em que, estima-se, 400 mil pessoas foram mortas (Johnson, 2001, p.657). Em maio de 1975, o número de mortos ainda não alcançava sua cifra final, ainda que a situação já tivesse sido antevista pelo Departamento de Estado, como aponta Johnson (2001).

O incidente com o Mayaguez gerou cinco reuniões do NSC para traçar maneiras de lidar com a situação. Premente, há o fator da experiência prévia, onde se aponta que "[c]ada tomador de decisões encara os eventos através do prisma de sua própria experiência. Ford estava no Congresso quando o Pueblo, um navio de vigilância eletrônica, foi capturado pela Coréia do Norte, durante o governo Johnson" (Kissinger, 2001, p.565). No caso deste navio, a tripulação foi mantida refém por onze meses e o impasse terminou somente com o que foi visto por Pyongyang como um pedido de desculpas, o qual foi propagandeado como uma grande vitória sobre a América. Assim, "[d]esde o início, Ford mostrou-se determinado a não permitir uma repetição de tal seqüência de eventos" (Kissinger, 2001, p.565). Portanto, deve-se levar em conta uma carga histórica com a capacidade de modificar a percepção que os atores têm do processo, nas linhas do debate entre Khong (1987; 2002) e Duffy $(2001 ; 2003)^{19}$.

A primeira reunião do NSC sobre o Mayaguez tem início ao meio-dia do dia 12 de maio de 1975, na sala do gabinete (Cabinet Room), e conta com a participação do presidente, do vice-presidente, dos secretários de Estado e Defesa, do chefe em exercício dos Chefes de Estado-Maior Reunidos, do diretor da Agência Central de Inteligência (CIA), de um 
auxiliar do secretário de Estado e de um da Defesa, do chefe de gabinete da Casa Branca, além de dois membros da equipe do NSC - Scowcroft e Smyser. A reunião do dia 12 serve, basicamente, para clarear o evento ocorrido. Primeiramente William Colby, diretor da CIA, explana que "[o] navio cargueiro americano Mayaguez foi capturado por comunistas do Khmer por volta das 3:15 PM horário local aproximadamente a sete ou oito milhas da ilha cambojana de Poulo Wei no Golfo da Tailândia." (apud United States of America, 1975a, p.2).

Adicionalmente, Colby ainda informa que "[n]ós não temos nenhuma informação sobre os motivos que levaram os comunistas do Khmer a capturarem o navio enquanto ele estava em rota de Hong Kong para Sattahip, Tailândia" (apud United States of America, 1975a, p.2). Há ainda a importante informação de que a região em que o navio trafegava é possivelmente um local rico em petróleo, disputado por comunistas cambojanos e por comunistas vietnamitas. Tem-se ainda como informação inicial de Colby que um navio panamenho foi capturado pelos comunistas do Khmer Vermelho na semana anterior, praticamente no mesmo local, e foi libertado posteriormente (United States of America, 1975a ). Não obstante, as informações sobre a localização do navio são inconsistentes e incompletas. É digno de nota que o diretor da CIA e o secretário de Defesa têm informações díspares.

Schlesinger, secretário de Defesa, é questionado por Ford sobre as opções de curso de ação ainda no início da reunião, mostrando um nível importante de iniciativa presidencial. É levantado pelo secretário que “[n]ós podemos adotar uma instância pacífica ou podemos ser ativos. Nós podemos tomar ações como confiscar bens cambojanos. Podemos juntar forças. Talvez possamos tomar uma pequena ilha como refém. Podemos também considerar um bloqueio" (apud United States of America, 1975a, p.3-4). As próprias opções mostram que ainda não há um fato coerentemente estabelecido que possa servir de guia para a reação, uma vez que o próprio secretário reconhece que "[n]ós não temos muitas informações sobre a situação atual" (Schlesinger apud United States of America, 1975a, p.4).

A primeira reunião ainda não conta com a informação do paradeiro preciso do navio, e é interessante apontar que há uma queixa por parte do secretário de Defesa sobre a demora na passagem da informação sobre a captura dentro da burocracia. Não obstante, os próprios presentes argumentam que este tipo de informação, em outros 
contextos, não chegaria aos últimos níveis decisórios de Washington (United States of America, 1975a). 0 contexto do atrapalhado fim da guerra no Vietnã fez com que esta questão de Mayaguez emergisse como importante para a administração Ford.

O contexto internacional é levado em alta consideração pelos participantes, principalmente com relação às possíveis conseqüências desta crise para a imagem já arranhada da nação americana (Kissinger, 2001). Assim, Kissinger levanta que “(...) nós temos dois problemas: o primeiro é como nós vamos recuperar o navio; o segundo é como os Estados Unidos vão se mostrar nessa situação" (apud United States of America, 1975a, p.4). Kissinger considera que se deve passar uma mensagem forte para os cambojanos, e que deve também haver uma ação que demonstre força e decisão. Para tal ação, os secretários de Estado e de Defesa e o presidente consideram, inicialmente, movimentações de navios da marinha americana que estejam na região. A opção de tomar o controle de pequenas ilhas cambojanas ou tomar navios cambojanos foi desconsiderada pelo pequeno volume de alvos disponíveis para que tais ações fossem empreendidas (United States of America, 1975a, p. 5-6).

A grande preocupação que norteia o tom da reunião do dia 12 de maio é como a informação sobre o Mayaguez será divulgada ao público. 0 presidente afirma que "[n]ós devemos colocar a demanda e nossa objeção ao ocorrido para a imprensa antes que eles consigam a história de outro lugar" (apud United States of America, 1975a, p.6). Assim, há uma grande preocupação com quais ações seguirão o discurso de repúdio ao ato cambojano e também com a compreensão, por parte dos líderes comunistas, da mensagem americana. Esta preocupação dá-se também em relação aos outros países do mundo, uma vez que a reação americana neste momento serviria de cálculo para reações futuras em eventos similares ${ }^{20}$.

Kissinger (2001) enfatiza que há uma preocupação presidencial em que não haja uma repetição do evento com o navio Pueblo na península coreana. Esta preocupação não é, porém, levantada por Ford, mas sim por seu vice-presidente, Nelson Rockefeller, que afirma:

[e]u penso que isso será visto como um teste. Eu penso que isto será julgado na Coréia do Sul. Eu me lembro do caso Pueblo. Penso que precisamos de algo 
forte e logo. Colocar uma mensagem ao público e deixar pessoas de prontidão não será suficiente.

Eu penso que uma resposta violenta está em ordem. 0 mundo deve saber que nós iremos agir e que nós iremos agir rapidamente. Nós devemos ter uma resposta imediata em termos de ação. Eu não sei se nós temos algum alvo que nós podemos atingir, mas nós devemos, certamente, considerar isto. Se eles conseguirem reféns, isto pode continuar para sempre" (apud United States of America, 1975a, p.8).

0 vice-presidente, em momento posterior, deixa claro seu pensamento sobre a situação e sobre como lidar com os comunistas cambojanos colocando que "(...) a não ser que os cambojanos saiam machucados, este padrão [de agressão] não será quebrado" (Rockefeller apud United States of America, 1975a, p.11). Portanto, tem-se uma urgência na tomada de alguma ação, imbuída no pensamento de que a imagem externa dos Estados Unidos está à prova a partir deste evento, um ponto recorrente durante todo o período da Guerra Fria ${ }^{21}$.

Em sintonia com o caráter assessor do NSC e com a concentração do poder decisório na figura de Ford, este coloca como resposta aos anseios relacionados à diplomacia pública que "[n]ós iremos emitir uma declaração e enviaremos a mensagem. Nós iremos mudar o curso do Coral Sea ${ }^{22}$. Nós iremos organizar uma força-tarefa em Subic e talvez colocá-la em ação. Talvez organizaremos uma força para tomar a ilha" (apud United States of America, 1975a, p.10) 23. Sobre estas opções, Ford requisita que as implicações e as formas de ação de cada uma sejam levantadas pelo Departamento de Defesa e sejam compiladas na tarde do mesmo dia ${ }^{24}$. 0 conteúdo da mensagem é resumido pelo chefe de gabinete da Casa Branca como "(...) uma declaração que explana os fatos, coloca que isto é um ato de pirataria, e falar que nós esperamos a libertação" (Rumsfeld apud United States of America, 1975a, p.13). 0 restante da reunião é ocupado por discussões menos substantivas sobre o tempo que certas ações levariam para acontecer e considerações iniciais sobre possíveis bombardeamentos e operações militares que tomariam o controle de territórios na região (United States of America, 1975a). O NSC volta a reunir-se somente no dia seguinte, 13 de maio de 1975.

No dia 13 de maio de 1975, o NSC reúne-se duas vezes, uma pela manhã e outra às 10 horas da noite (United States of America, 1975b e 1975c). Durante a manhã são discutidos pontos importantes sobre a localização 
do navio e sobre possíveis cursos de ação. Assim, tem-se que ao início da reunião, "[o] Mayaguez está ancorado perto da ilha de Koh Tang, cerca de 30 milhas a sudoeste de Kompong Som" (Colby apud United States of America, 1975b, p.2). Neste ponto, é indicada certa incoerência entre as informações fornecidas pelo Pentágono no dia anterior e as informações correntes, pois se esperava que o navio estivesse se movendo em direção ao porto.

Não obstante, Schlesinger (apud United States of America, 197b) coloca que a informação de que o navio estaria atracado no porto nesse momento era apenas uma estimativa. São conseguidas informações mais precisas, que são apresentadas na reunião do dia 13 de maio. Entretanto, como a interpretação foi diferente, o vice-presidente Rockefeller coloca que "[h]ouve um ponto que foi um grande engano ontem. Você tinha a informação de que o navio americano já estava no porto em Kompong Som. Isto te negou uma opção, que seria de tentar não permitir que o navio fosse levado ao porto." (apud United States of America, 1975b, p.4). Esta questão é colocada pelo presidente de forma definitiva e representa uma das grandes preocupações da reunião: “[e]u realmente penso que temos de ter certeza de nossos fatos. Durante a noite, Brent [Scowcroft, assessor para Segurança Nacional] me deu uma série de relatórios diferentes sobre a localização do navio e sobre o que ocorria" (apud United States of America, 1975b, p.4). 0 ponto era assegurar a precisão da informação que a inteligência americana conseguia. Assim, Colby coloca que no momento "[n]ós pensamos que o navio estava fora da ilha, como eu pontuei. Nós entendemos que estão desembarcando pessoas. Nós vimos isto" (apud United States of America, 1975b, p.5). Portanto, é com base nestas informações que os participantes da reunião da manhã do dia 13 trabalham ${ }^{25}$.

Colby e Jones (apud United States of America, 1975b), respectivamente diretor da CIA e chefe em exercício do JCS, afirmam que os americanos foram desembarcados, e estão na ilha em que o navio está ancorado. Assim, a decisão de bloquear qualquer movimentação do navio é tomada, para que os americanos possam sempre saber o posicionamento destes. É apontado que somente no caso de condições climáticas extremamente desfavoráveis não se poderia acompanhar as movimentações dentro do navio (United States of America, 1975b ). Ford demonstra uma grande preocupação com o atraso de informações e é informado de que a transmissão está sendo feita com prioridade máxima. Tem sempre de ocorrer, porém, algum tratamento da 
informação (United States of America, 1975b, p. 7-8). Schlesinger (apud United States of America, 1975b) aponta que as opções de ação foram revisadas pelo Departamento de Defesa e que seriam necessárias muitas tropas para tomar Kompong Som. O ideal seria impedir a movimentação do navio, curso de ação que é adotado.

Existem ainda ponderações sobre como os militares americanos poderiam invadir o navio (United States of America, 1975b, p. 12). Scowcroft (apud United States of America, 1975b) aponta que seriam duas as opções de operação: uma contra o navio e outra contra a ilha. Ford (apud United States of America, 1975b) organiza as opções em quatro momentos e tipos de ação: i) não permitir que navios saiam da ilha; ii) não permitir que navios cheguem à ilha; iii) preparar o desembarque de militares para a tomada do navio; e iv) levar marines para a ilha. Estes passos colocados pelo presidente são a decisão final de ação, que é trabalhada até o fim da reunião.

É digno de nota que na reunião do dia 12 de maio e na primeira reunião do dia 13 de maio, o vice-presidente utiliza a mesma metáfora para demonstrar a necessidade de ação decisiva ${ }^{26}$. Rockefeller (apud United States of America, 1975a, 1975b) acredita que os comunistas continuarão atacando até que encontrem resistência. Este curso de ação, segundo Rockefeller, é formulado por Mao e é representativo do tipo de raciocínio que os americanos acreditavam pertencer aos comunistas. Assim, Rockefeller queria que os comunistas encontrassem forte resistência, almejando, desta forma, detê-los.

A reunião da noite do dia 13 de maio 27 é convocada devido a um dilema enfrentado por um piloto no momento de implementar as ordens para que nenhum navio se deslocasse da ilha ${ }^{28}$. 0 piloto questiona Washington sobre movimentações de um navio que pode ter cidadãos americanos, e requisita informações sobre a possibilidade de afundar ou não o navio. 0 piloto informa ainda que já fez uso de armas não letais para tentar parar o navio. Assim, o presidente resolve a questão de forma simples e decisiva, dizendo que "[e]u dei a ordem na reunião para que todos os navios fossem parados" (apud United States of America, 1975c, p.4). Ford reforça a ordem dada, lembrando que a ordem já havia sido estipulada anteriormente. Os participantes da reunião lembram, ainda, que é importante impedir que os comunistas consigam fazer reféns em solo ${ }^{29}$. 
Durante o restante da reunião, os participantes focam-se em discussões mais técnicas sobre o tempo de desdobramento de forças e as opções de ação. Os participantes mostram-se decididos a tomar algum tipo de ação e já traçam opções diferentes, que ainda dependem do tempo de desdobramento de forças para sua execução. Kissinger encerra a reunião definindo pontos relevantes para um anúncio público sobre o bloqueio de todos os navios: "[e]le [o porta-voz] deve explicar porque nós estamos fazendo isto [bloqueio de movimentação]. Ele deve dizer que isto foi ordenado por você [Ford], executado pelo Conselho de Segurança Nacional, e depois não responder a outras questões" (apud United States of America, 1975c, p.23).

No dia 14 de maio, o NSC volta a se reunir, com, fundamentalmente, os mesmos participantes das reuniões anteriores ${ }^{30}$. 0 ponto central da reunião, assim como a da noite do dia 13 de maio, foi logística militar e detalhes operacionais, focando-se no tempo de desdobramento das forças e na quantidade destas, devido à velocidade do desdobramento ${ }^{31}$. A situação apresenta uma modificação interessante, que foi a presença de navios inimigos em uma quantidade mais precisa do que a presente em informações anteriores. Colby (apud United States of America, 1975d, p.2) diz que “(...) existem 24 navios armados na proximidade de Kompong Som - 13 navios da guarda costeira, 10 navios de patrulha fluviais, um perseguidor de submarino". Assim, um dos pontos principais da reunião foi a presença de forças comunistas na região e, provavelmente, em alerta; mostrando que as opções de operações americanas poderiam encontrar resistência forte, inclusive porque "[e]m força terrestre, forças combatentes comunistas cambojanas em Kompong Som totalizam umas duas mil tropas" (Colby apud United States of America, 1975d, p.2). Entretanto, "[d]os cinco navios cambojanos com artilharia que foram desdobrados ontem à noite, (horário de Washington) no entorno da ilha Koh Tang, três foram afundados por aeronaves americanas" (Colby apud United States of America, 1975d, p.4); mostrando que o bloqueio da circulação promovido pelos americanos tem funcionado.

0 estado das forças foi colocado de forma clara por Ford (apud United States of America, 1975d, p.7), como "[p]ortanto, neste momento, o Holt está no local, o Coral Sea está pronto, e o Wilson está lá em breve"32. Jones (apud United States of America, 1975d), chefe em exercício do JCS, destaca três elementos importantes na ação militar americana: i) os marines recuperarem o navio e assegurarem sua integridade; ii) a ação 
dos helicópteros para auxiliar na tomada do Mayaguez; e iii) os assaltos táticos aéreos. A partir destes três pontos levantados por Jones na reunião, Kissinger (2001, p.581-582) apontou três fontes de preocupação na execução da operação: “(...) a recaptura do Mayaguez, o desembarque em Koh Tang e o ataque aéreo ao continente". Apesar destas preocupações, esta foi a base da operação militar que foi desenhada e aprovada pelo presidente no NSC, uma vez que avalia-se que esta leva em consideração todos os problemas que os americanos têm de lidar na situação.

Surgiu ainda, na reunião, a idéia de transmitir um ultimato para os cambojanos, “(...) que iria dizer que, dentro de tantas horas, a não ser que vocês nos digam que estão libertando os americanos, haverá ataques aéreos" (Jones apud United States of America, 1975d, p.15). As discussões posteriores levam a entender que o ultimato foi uma boa opção que pode ser utilizada, no limite, como uma ação de salva-moral (face-save), uma vez que teria tido um alerta prévio do bombardeio. Porém, o ultimato não faz com que nenhuma ação militar fosse postergada, uma vez que Ford não desejava nenhum atraso ou quebra de tempo de ação militar devido ao ultimato ${ }^{33}$. Kissinger (apud United States of America, 1975d, p.21) coloca que “(...) nós podemos dar um ultimato que é crível. Nós temos muitas coisas que podemos fazer posteriormente. (...) Então estaremos em um teste de longo prazo. Nós não ganharemos nada não alvejando Kompong Som". A necessidade da manutenção da operação, como já planejada, fica ainda mais clara para os participantes, quando se coloca que "[n]ós temos uma obrigação de resgatar os americanos ou verificar se eles estão lá" (Schlesinger apud United States of America, 1975d, p.22).

0 restante da reunião foi ocupado com preocupações sobre como difundir as informações para o público interno e externo, ou seja: com a parte de diplomacia pública ${ }^{34}$. As ações foram voltadas, principalmente, para informar os aliados da Organização do Tratado do Atlântico Norte (OTAN), as lideranças do Congresso e o público americano em geral. A grande preocupação era a reação das lideranças do Congresso, principalmente em relação às provisões do Ato de Poderes de Guerra e as possíveis implicações do engajamento militar limitado desta crise ${ }^{35}$.

O NSC volta a reunir-se no dia 15 de maio de 1975, após o fim das operações militares planejadas nas reuniões anteriores, porém já com três tópicos em sua agenda, em oposição a lidar somente com a crise do 
Mayaguez, como havia sido nos dias anteriores, indicando que a urgência já havia passado ${ }^{36}$. Colby (apud United States of America, 1975e) fornece um relatório detalhado sobre os eventos que ocorreram após a ação militar, porém sem muitos dados conclusivos, pois ainda eram esperados alguns relatórios de atividade. Os números finais de perdas americanas são "[n]ós perdemos três helicópteros na operação. 0 equipamento sofreu muitos danos de batalha. Nossas baixas foram 1 morto em ação, 1 desaparecido e 30 feridos." (Jones apud United States of America, 1975e, p.5). Kissinger (2001) aponta que Ford ficou insatisfeito com o desempenho das forças armadas na ocasião, principalmente com a passagem deficiente de ordens e a reinterpretação de algumas destas. Assim, o presidente encerra de forma seca a reunião sobre o Mayaguez, dizendo "[f]oi um trabalho bem feito. Podemos agora prosseguir para o próximo item em nossa agenda" (Ford apud United States of America, 1975e, p.6) ${ }^{37}$. Desta maneira, o Mayaguez sai da agenda do NSC.

\section{Ford em Mitchell}

No período da crise do Mayaguez, o processo decisório de Ford, dentro do NSC, apresentou traços de um processo de decisão formal tanto do tipo altamente centralizado, quanto de um fracamente centralizado, de acordo com a tipologia de Mitchell (2005). Sem sombra de dúvida, o presidente Ford teve um papel de liderança e de agente fornecedor de pensamentos iniciais para o desenvolvimento em políticas e ações concretas, o que fez com que o sistema fordista tivesse uma tendência para a alta centralização ${ }^{38}$. Ford tomou a iniciativa de determinar que os Estados Unidos devessem ter uma reação forte diante do seqüestro do Mayaguez.

Adicionalmente, o presidente teve um papel de liderança nas discussões, chegando inclusive a levantar opções diferentes em dados momentos. Não obstante, Henry Kissinger, na época ainda assessor de segurança nacional e secretário de Estado, teve um papel de homem de confiança do presidente, uma vez que algumas das frustrações de Ford somente podem ser percebidas através de relatos secundários de Kissinger ${ }^{39}$. Scowcroft já pode, no entanto, ser considerado o assessor para segurança nacional de facto, apesar de ter um papel menor em relação ao papel desempenhado por Kissinger anteriormente ${ }^{40}$. 
Assim, consideramos que Ford apresenta as seguintes características do sistema formal altamente centralizado: i) líder avalia as opções apresentadas, uma vez que Ford julgou em diversos momentos a velocidade dos desdobramentos das tropas em relação ao tempo de ação necessário para os atos políticos. Em muitos momentos, o próprio Ford tentou organizar o tempo das ações; ii) líder expressa preferência geral moldando a consideração das opções, pois temos que Ford expressou já na primeira reunião o desejo de oferecer aos cambojanos uma resposta forte. Esta linha foi seguida nas outras reuniões; iii) processo decisório bem definido e ordeiro, pois, durante todas as reuniões, Ford deixou claro que suas ordens são as finais e irrita-se quando elas não são cumpridas como colocadas.

Do sistema formal com baixa centralização temos: i) guardião age como um representante honesto e apresenta opções - como o próprio Ford indicou, Scowcroft sempre passa as atualizações que julga necessárias, mesmo durante a noite, fornecendo as informações no menor tempo possível para a solução da crise; e ii) líder escolhe entre as opções apresentadas, uma vez que Ford selecionou os planos e as opções militares que são apresentadas, o que, no limite, pode ser associado com o processo ordeiro de suas reuniões para a solução da crise. Portanto, conclui-se que o sistema de Ford apresentou traços do formalismo altamente centralizado de Nixon. Este contém, no entanto, modificações que fornecem uma diferenciação em relação a seu antecessor.

\section{Conclusão}

O processo de decisório na situação com o navio Mayaguez mostrou que Ford conseguiu assumir a presidência e moldar às suas necessidades o aparato deixado por Nixon, sendo notável a diferenciação entre as duas administrações. A hibridez do sistema NSC sob a presidência de Ford é um dos indicativos mais significativos da mudança que ocorreu enquanto o governo continuava. Portanto, Ford tem o mérito de promover suas modificações no campo da segurança nacional, enquanto mantinha o funcionamento regular do governo. A identificação tipológica de Mitchell (2005) serve como um forte sinal de que a administração Ford conseguiu introduzir características próprias no processo, mostrando que o Conselho de Segurança Nacional realmente deve ser adaptado às necessidades do ocupante da Casa 
Branca. Em conclusão, o estudo da situação envolvendo o Mayaguez nos permite afirmar que o NSC é moldado às necessidades presidenciais, $\mathrm{e}$ que há uma diferença forte, representada tipologicamente, entre as duas administrações mais próximas da história recente americana. 


\section{Referências Bibliográficas}

BARTELS, Frederico; RIBEIRO, Cíntia. Decision-Making in American Foreign Policy: The Cambodian Incursion, 1970. In: CALDEIRA, A.H.; LIMA, B.P.F.G.; BARBOSA, I.A.V. (Org.). Pensando a Ásia nas Relações Internacionais: Idéias e Perspectivas do Passado e do Presente. Belo Horizonte: PUC Minas, Departamento de Relações Internacionais, FUNAG, 2007, p. 53-90.

BUNDY, William. A Tangled Web: The Making of Foreign Policy in the Nixon Presidency. New York: Hill and Wang, 1998.

DEPARTMENT OF STATE. United States of America. Under Secretary for Public Diplomacy and Public Affairs. Washington, DC, 2008. Disponível em: <http://www.state.gov/r/>. Último acesso em 16 jan. 2008.

DUFFY, Gavan. Give Structure Its Due: Political Agency and the Vietnam Commitment Decisions. Japanese Journal of Political Science, v. 2, n. 2, 2001, p. 161-175.

DUFFY, Gavan. The Agent-Structure Co-Constitution and the Vietnam Commitment Decisions: A Rejoinder to Yuen Foong Khong. Japanese Journal of Political Science, v. 4, n. 1, 2003, p.103-111.

FORD, Gerald. A Conversation with President Ford. In.: LOBEL, Aaron (ed.). Presidential Judgment: Foreign Policy Decision Making in the White House. Hollis: Hollis Publishing Company, 2001, p.79-88.

GARTHOFF, Raymond L. Détente and Confrontation: American-Soviet Relations From Nixon to Reagan. Washington, D.C.: The Brookings Institution, 1985.

GEORGE, Alexander L. Presidential Decisionmaking in Foreign Policy: The Effective Use of Information and Advice. Boulder: Westview Press, 1980.

GOULD, Lewis L. Grand Old Party: A History of the Republicans. Nova Iorque: Random House, 2003.

HAMILTON, Alexander; MADISON, James; JAY, John. The Federalist Papers. 1788. Nova Iorque: Bantam Books, 1982.

HILL, Christopher. The Changing Politics of Foreign Policy. New York: Palgrave Macmillan, 2003. 
HILSMAN, Roger. The Politics of Policy Making in Defense and Foreign Affairs: Conceptual Models and Bureaucratic Politics. Second Edition. Englewood Cliffs: Prentice-Hall, Inc., 1987.

HUDSON, Valerie M. Foreign Policy Analysis: Actor-Specific Theory and the Ground of International Relations. Foreign Policy Analysis, v. 1, 2005, p. 1-30.

HUDSON, Valerie M. Foreign Policy Analysis: Classic and Contemporary Theory. Lanham: Rowan \& Littlefield Publishers, Inc, 2007.

INDERFURTH, K.F.; JOHNSON, L.K. Fateful Decisions: Inside the National Security Council. Nova Iorque: Oxford University Press, 2004

JAVITS, Jacob K. The Congressional Presence in Foreign Relations. Foreign Affairs, v. 48, n. 2, 1970, p.221-234.

JOHNSON, Paul. Modern Times: The World form the Twenties to the Nineties. Revised Edition. Nova Iorque: Perennial Classics, 2001.

JOHNSON, Richard T. Managing the White House: An Intimate Study of the Presidency. Nova Iorque: Harper \& Row, Publishers: 1974.

JORDAN, A.A.; TAYLOR, Jr., W.J.; MAZARR, M.J. American National Security. Fifth Edition. Baltimore e Londres: The Johns Hopkins University Press, 1999.

KHONG, Yuen Foong. Seduction by Analogy in Vietnam: The Malaya and Korea Analogies. 1987. In: IKENBERRY, G. John. American foreign policy: theoretical essays. 5th ed. New York: Pearson, Longman, 2005.

KHONG, Yuen Foong. The Agent-Structure Debate and America's Vietnam Options: A Reply to Professor Gavan Duffy. Japanese Journal of Political Science, v. 3, n.1, 2002, p.1-23.

KIMBALL, Jeffrey. Nixon's Vietnam War. Lawrence: University Press of Kansas, 1998.

KISSINGER, Henry A. Ending the Vietnam War: a history of America's involvement in and extrication from the Vietnam War. New York: Simon \& Schuster, 2003.

KISSINGER, Henry. Memórias: volume 3: anos de renovação. Rio de Janeiro: Univer Cidade, 2001. 
KOLODZIEJ, Edward A. The National Security Council: Innovations and Implications. Public Administration Review, vol. 29, no. 6, novembrodezembro 1969, p. 573-585.

MENGES, Constantine C. Inside the National Security Council: The True Story of the Making and Unmaking of Reagan's Foreign Policy. Nova Iorque: Simon and Schuster, 1988.

MITCHELL, David. Making Foreign Policy: Presidential Management of the Decision-Making Process. Aldershot: Ashgate Publishing Limited, 2005.

NEOCLEOUS, Mark. From Social to National Security: On the Fabrication of Economic Order. Security Dialogue, v. 37, n. 3, 2006, p.363-384.

NEUSTADT, Richard E. Presidential Power and the Modern Presidents: The politics of leadership from Roosevelt to Reagan. Edição revisada. Nova Iorque: Free Press, 1990.

NIXON, Richard M. The Memoirs of Richard Nixon. New York: Grosset \& Dunlap. 1978.

NOLAN, Keith William. Into Cambodia: Spring Campaign, Summer Offensive, 1970. Novato: Presidio Press, 1990.

PRADOS, John. Keepers of the Keys: A History of the National Security Council from Truman to Bush. Nova Iorque: William Morrow and Company, Inc, 1991.

ROCKMAN, Bert A. America's Departments of State. 1981. In: INDERFURTH, Karl F.; JOHNSON, Loch K. Fateful Decisions: Inside the National Security Council. New York: Oxford University Press, 2004, p. 289-307.

ROTHKOPF, David J. Running the World: the Inside Story of the National Security Council and the Architects of American Power. Nova Iorque: Public Affairs, 2005.

SCOWCROFT, Brent. Judgment and Experience: George Bush's Foreign Policy. In: LOBEL, Aaron (ed.). Presidential Judgment: Foreign Policy Decision Making in the White House. Hollis: Hollis Publishing Company, 2001, p. 103-115.

SORENSEN, Theodore C. Decision-Making in the White House: The Olive Branch of the Arrows. Nova Iorque: Columbia University Press, 2005. 
TOCQUEVILlE, Alexis de. Democracy in America. The Complete and Unabridged Volumes I and II. 1835. Nova Iorque: Batnam Books, 2004.

TOWER, John G. Congress versus the President: The Formulation and Implementation of American Foreign Policy. Foreign Affairs, v. 60, n. 2, inverno 1981/1982, p.229-246.

TOWER; John; MUSKIE, Edmund; SCOWCROFT, Brent. The Tower Commission Report: the Full Text of the President's Special Review Board. Nova Iorque, Bantam Books, Inc., 1987.

U.S. CONGRESS. The National Security Act of 1947. 1947. In: INDERFURTH, K.F.; JOHNSON, L.K. Fateful Decisions: Inside the National Security Council. Nova Iorque: Oxford University Press, 2004, p. 24-26.

UNITED STATES CONGRESS. United States of America. The War Powers Act of 1973. Washington, DC. 7 de novembro, 1973. Disponível em:

<http://cwx.prenhall.com/bookbind/pubbooks/dye4/medialib/docs/ warpower.htm>. Último acesso em 16 jan. 2008.

UNITED STATES OF AMERICA. National Security Council. Minutes National Security Council Meeting. 12 de maio, 1975. 1975a. Disponível em: <http://www.fordlibrarymuseum.gov/library/document/nscmin/750 512.pdf>. Último acesso em 25 dez. 2007.

UNITED STATES OF AMERICA. National Security Council. Minutes National Security Council Meeting. 13 de maio, 1975 (manhã). 1975b. Disponível em: <http://www.fordlibrarymuseum.gov/library/document/nscmin/750 513.pdf>. Último acesso em 10 jan. 2008.

UNITED STATES OF AMERICA. National Security Council. Minutes National Security Council Meeting. 13 de maio, 1975 (noite). 1975c. Disponível em: <http://www.fordlibrarymuseum.gov/library/document/nscmin/750 5132.pdf>. Último acesso em 10 jan. 2008.

UNITED STATES OF AMERICA. National Security Council. Minutes National Security Council Meeting. 14 de maio, 1975. 1975d. Disponível em: <http://www.fordlibrarymuseum.gov/library/document/nscmin/750 514.pdf>. Último acesso em 15 jan. 2008. 
UNITED STATES OF AMERICA. National Security Council. Minutes National Security Council Meeting. 15 de maio, 1975. 1975e. Disponível em: <http://www.fordlibrarymuseum.gov/library/document/nscmin/750 515.pdf>. Último acesso em 15 jan. 2008.

UNITED STATES OF AMERICA. National Security Council. National Security Council Meeting Minutes. Washington, DC, 2001. Disponível em:

<http://www.fordlibrarymuseum.gov/library/document/nscmin/minl ist.htm>. Último acesso em 9 dez. 2007.

UNITED STATES OF AMERICA. National Security Council. National Security Decision Memorandum 265. Washington, 9 de agosto, 1974. 1974a. Disponível em: <http://www.fordlibrarymuseum.gov/library/document/nsdmnssm/n sdm265a.htm>. Último acesso em 9 dez. 2007.

\section{Notas}

1 Esta e as demais citações de originais em língua estrangeira foram livremente traduzidas para este artigo pelo autor.

20 conceito de segurança nacional surge no pós-Segunda Guerra e passa a ser utilizado amplamente a partir do estabelecimento do Ato de Segurança Nacional de 1947 e é definido por Neocleous (2006) como sendo um termo associado com política externa e política de defesa. Jordan, Taylor, Jr. e Mazarr (1999) apontam que o conceito de segurança nacional vai além da defesa nacional e engloba elementos econômicos e culturais, principalmente aqueles que possam afetar os valores da sociedade em questão.

${ }^{3}$ Apesar da plasticidade do Conselho, o Ato de Segurança Nacional de 1947 define os componentes estatutais que são: o presidente, o vice-presidente, o secretário de Estado e o secretário de Defesa. Adicionalmente, o Conselho poderia contar com outros conselheiros que seriam convocados pelo presidente de acordo com a necessidade dos assuntos em deliberação (U.S. Congress, 1947).

${ }^{4} 0$ Ato de Segurança Nacional de 1947 é o marco legal do NSC. Além de criá-lo e determinar a função do Conselho, o Ato ainda cria algumas das posições que compõem o mesmo. Neste sentido, a criação da Agência Central de Inteligência (CIA), da unificação dos departamentos militares sob controle civil do Departamento de Defesa (DOD), a criação do Chefes de Estado-Maior Reunidos (JCS - Joint Chiefs of Staff), e a própria figura do assistente de segurança nacional são frutos do esforço de integrar as diferentes esferas da segurança nacional, que tem seu pináculo no NSC (U.S. Congress, 1947).

5 Mesmo o NSC da administração Reagan, considerado por Rothkopf (2005) como o crepúsculo na história do Conselho, recebe uma grande atenção tanto por parte dos 
acadêmicos, quanto por parte dos assessores da administração na época (Menges, 1998).

${ }^{6}$ Este papel dual é extremamente importante, pois dentro do NSC, os secretários de Estado, de Defesa e os chefes de qualquer outra burocracia governamental têm de levar em consideração que não são somente assessores presidenciais, mas também representantes de grupos de pressão específicos. Cf. Rothkopf, 2005, para mais detalhes sobre esta questão.

${ }^{7}$ As reclamações advêm da maneira como o presidente Roosevelt conduziu a guerra. Cf. Inderfurth; Johnson, 2004.

${ }_{8}^{8}$ Principalmente a questão de pesos e contra-pesos (checks and balances) e os artigos de 47 a 50 sobre a separação não absoluta entre os poderes. Pois estes elementos mostram a importância da redundância, definida enquanto multiplicidade de fontes do mesmo poder, na formação social americana.

${ }^{9}$ Sem investigações mais profundas, podemos dizer que a condução das relações internacionais americanas está dividida entre o Departamento de Estado, o Departamento de Defesa e o Departamento de Comércio. Isto sem levar em consideração que o Departamento do Tesouro tem uma grande influência na política financeira internacional que os Estados Unidos conduzem.

10 Tower, Muskie e Scowcroft (1987) apontam para esta mudança que ocorre ao longo do tempo no Conselho. E, nesse sentido, cada administração adotou uma postura diferente para a equipe NSC, passando desde o tamanho dela até as funções que lhe são colocadas.

11 Bartels e Ribeiro (2007) provêm uma análise do sistema do NSC durante a administração Nixon vis-à-vis o processo de tomada de decisão que levou à incursão ao Camboja durante a Guerra do Vietnã, mostrando os toques personalistas que a máquina governamental emula dos presidentes.

${ }^{12} \mathrm{~A}$ atuação do secretário de Estado, William P. Rogers, foi reduzida às questões que não são prioridades do governo Nixon, como a situação no Oriente Médio ou na América Latina (Bundy, 1998).

${ }^{13}$ Johnson (1974) coloca que a formalidade do sistema depende, em grande parte, da disciplina na aplicação das regras que são escolhidas para geri-lo.

${ }^{14}$ A tipologia desenvolvida por Mitchell (2005) advém de esforços anteriores para a construção de tipologias de sistemas de aconselhamento, principalmente por Johnson (1974) e George (1980). Porém a tipologia de Mitchell (2005) passa a levar em consideração a centralização do sistema na figura presidencial e não só a forma pela qual o sistema é organizado. Há, portanto, a construção de quatro possibilidades a partir de duas variáveis, em oposição à tipologia desenvolvida por Johnson (1974) e George (1980), que só leva em consideração a formalização do sistema, ou seja, se este é formal, colegiado ou competitivo.

15 A tipologia de Mitchell (2005) é colocada como sendo aplicável a sistemas de aconselhamento genericamente, e o próprio autor trabalha com o NSC ao longo de sua obra como o sistema de aconselhamento que serve de exemplo para seus estudos de caso. No limite, podemos colocar que Mitchell (2005) praticamente reduz suas análises de sistemas de aconselhamentos ao Conselho.

${ }^{16} \mathrm{~A}$ avaliação do líder se faz presente em $75 \%$ dos casos, a expressão das preferências do líder em 100\% dos casos, a função do guardião em $87 \%$, a exclusão de dissidentes 
em $87 \%$ e a solução dominante em $87 \%$ dos casos estudados por Mitchell (2005). Cf. Mitchell, 2005, p.77.

17 Respectivamente, Estado e Defesa.

18 O Camboja passou por diversas transformações no período da Guerra do Vietnã. No ano de 1975, o governo dos comunistas do Khmer Vermelho estava no poder. Os comunistas cambojanos eram particularmente cruéis e sanguinários, pontos descritos por Nolan (1990) e Johnson (2001). Cf. Johnson (2001, p.654-658).

19 Estes autores exploram a questão da influência da analogia histórica no processo decisório atual, mostrando que existe a possibilidade desta influência, porém discordam sobre a forma que isto pode ocorrer. Cf. George, 1980.

${ }^{20}$ Este ponto reforça o aprendizado por analogias colocado por Khong (1987) e que é explorado por Kissinger (2001) e Garthoff (1985).

${ }^{21}$ Este ponto aparece de forma bem latente na administração Nixon. Cf. Kimball, 1998, Bundy, 1998.

${ }^{22}$ Coral Sea era uma embarcação da marinha americana que estava próxima da região.

230 navio Coral Sea é um porta-aviões que estava em rota para a Austrália para funções cerimoniais. Em Subic é onde se localiza a força americana disponível mais próxima do local. A ilha a qual Ford faz referência é a ilha que os vietnamitas e cambojanos disputam, próxima a onde o Mayaguez foi capturado. Estas informações são fornecidas pelo secretário de Defesa e pelo diretor da CIA no curso da reunião do dia 12 de maio de 1975. Cf. United States of America, 1975a.

${ }^{24}$ A reunião ocorre das 12:05 PM até as 12:50 PM. Cf. United States of America, 1975a.

25 Os participantes são: o presidente, o vice-Presidente, o sub-secretário de Estado para Assuntos Políticos, o secretário de Defesa, o chefe em exercício do JCS, o diretor da CIA, o vice-secretário de defesa, Rumsfeld, Hartmann, Marsh pela Casa Branca e Scowcroft e Smyser pelo NSC.

${ }^{26}$ A metáfora sobre o comportamento de comunistas em si é "Probe with bayonets. If you encounter steel, withdraw. If you encounter mush, continue", que pode ser traduzida para "Sonde com baionetas. Se você encontrar aço, recue. Se você encontrar batata, continue". Esta metáfora também foi usada por Nixon para pensar o comportamento soviético. Cf. Nixon, 1978.

27 A reunião inicia-se às 10:40 PM e termina às 12:25 AM. Cf. United States of America, $1975 c$.

${ }^{28}$ Cf. United States of America, 1975a e 1975b para as ordens iniciais.

29 Esta questão dos reféns é levantada diversas vezes, por ser um dos indícios de que poderia ter uma nova situação como a do incidente do navio Pueblo na Coréia do Norte, onde devido à presença de reféns a situação se arrastou. Cf. Kissinger, 2001.

30 Os participantes da reunião do dia 14 são: Ford, Rockefeller, Kissinger, Schlesinger, Jones, Colby, Ingersoll, Clemente, Holloway, Rumsfeld, Marsh, Martmann, Buchen, Scowcroft, Smyser. Cf. United States of America, 1975d. As reuniões anteriores estão registradas em United States of America, 1975a, 1975b, 1975c.

${ }^{31}$ Cf. United States of America, 1975d. 
32 Holt, Coral Sea e Wilson são embarcações das forças armadas americanas que deslocaram-se para a região para auxiliar na crise. Mais detalhes podem ser encontrados em United States of America, 1975a, 1975b, 1975c, 1975d, 1975e.

33 Esta atitude relutante em relação a atrasos nas ações militares é explorada por Kissinger (2001) como sendo proveniente de experiências anteriores do presidente com atitudes do Pentágono, principalmente a visão do Pentágono que não quer ver-se como o centro de mais falhas operacionais diante da sociedade americana. Kissinger (2001) coloca que isto fica claro no certo distanciamento que o secretário de Defesa e o chefe em exercício do JCS tomam em relação aos debates no NSC.

34 A diplomacia pública é um dos ramos da diplomacia mais importantes durante a Guerra Fria e ainda tem uma grande importância atualmente. As responsabilidades primárias lidam com a imagem que o Estado transmite de si. Cf. Department of State, 2008.

${ }^{35}$ Cf. United States Congress, 1973 para maiores informações. Sem maiores detalhes, o Ato requer que qualquer engajamento militar seja reportado para o Congresso e que haja consultas com o Congresso no caso de certos tipos de ação. Este ponto remonta ao debate representado por Javits (1970) e Tower (1981/1982) sobre os papéis relativos do Poder Legislativo e Executivo na formulação de política externa americana. Debate este que tem sua origem no próprio sistema democrático americano sobre a divisão dos três poderes, principalmente entre o Legislativo e o Executivo. Cf. Hamilton, Madison e Jay (1788/1982).

36 Cf. United States of America, 1975e. Os três tópicos são: i) a apreensão de navio americano por autoridades cambojanas; ii) negociações do Canal do Panamá; e iii) Oriente Médio.

37 Kissinger (2001) e United States of America (1975e) apontam que minutos antes desta fala, Ford chamou Kissinger para fora da sala e expressou algumas de suas frustrações com o desempenho institucional do Pentágono e do aparato militar na ocasião, porém por considerar que o resultado final foi bem sucedido, este "deixou certos detalhes passarem". Cf. Kissinger, 2001, p.586-590.

38 Ford em nenhum momento apresenta indícios de um sistema colegiado, uma vez que o presidente sempre coloca-se como o tomador de decisão e não há muita divisão do poder decisório, nem delegação.

39 Cf. Kissinger, 2001. Em suas memórias, o secretário de Estado de Ford coloca detalhes importantes sobre o pensamento do presidente sobre o que este considera como uma falha de transmissão de comandos militares através do Pentágono, principalmente sobre as ordens que não foram cumpridas em sua totalidade a respeito da interceptação de navios.

40 Cf. Bundy, 1998, Kimball, 1998. Através de United States of America, 1975a, 1975b, $1975 c, 1975 d$ e 1975e, pode-se perceber que Scowcroft tem um papel menos ativo, agindo mais próximo do guardião (gatekepper). Papel este que é pensado por alguns como o ideal para o cargo de assessor de Segurança Nacional. Cf. Prados, 1991. 